\title{
A Compact UWB Antenna using Planar-Patterned Structures
}

\author{
Md. Moinul Islam ${ }^{1,2, *}$, Mohammad Rashed Iqbal Faruque Islam, and Mohammad \\ Tariqul Islam² \\ ${ }^{1}$ Space Science Centre, Universiti Kebangsaan Malaysia, Selangor, Malaysia \\ ${ }^{2}$ Department of Electrical, Electronic and Systems Engineering, Universiti Kebangsaan \\ Malaysia, Selangor, Malaysia \\ \{mmoiislam, rashedgen, titareq\} @yahoo.com
}

\begin{abstract}
A compact UWB antenna has been presented based on planar-patterned structures. This antenna's radiating element has been constructed four identical unit cells along one axis fed with a microstrip line. This antenna is printed on low dielectric FR4 material of $1.6 \mathrm{~mm}$ thickness with $18.97 \mathrm{~mm} \times 27.16 \mathrm{~mm}$ antenna size. High-frequency structural simulator (HFSS) has been adopted in this research for performing all the simulations. The $16.84 \mathrm{GHz}$ (3.07 to $19.91 \mathrm{GHz}$ ) impedance bandwidth has been achieved in measurements through the antenna.
\end{abstract}

Keywords: Microstrip antenna, planar-patterned structure, UWB

\section{Introduction}

At present, the demand of wireless communication in short distance has been raised sharply. The Federal Communications Commission (FCC) has approved 3.1-10.6 GHz frequency range as a standard for short distance unlicensed wireless communication [1]. UWB antennas play an important role in wireless communications due to having attractive properties such as low cost, miniaturization, low interferences, high data transmission rate, and low spectral power density. It is not so easy to design a miniaturized antenna for operating UWB frequencies and also still a challenging now.

Many UWB antennas are reviewed in the study. Shakib presented an UWB antenna with a perpendicular ground plane. The antenna dimension is raised for this ground plane. As a result, integration is very difficult with microwave integrated circuits [2]. Nordin [3] explained a planar antenna $(0.21 \lambda \times 0.20 \lambda$ at $2.90 \mathrm{GHz})$ operating in UWB frequency. The measured impedance bandwidth was $7.0 \mathrm{GHz}(2.9-9.9 \mathrm{GHz})$. But, the reviewed antenna did not cover the standard FCC approved UWB band (3.1-10.6 GHz) completely. Islam [4] reviewed a planar antenna $(0.20 \lambda \times 0.29$ $\lambda$ at $3.10 \mathrm{GHz}$ ) operating in UWB frequency. The measured impedance bandwidth was more than $11.90 \mathrm{GHz}$ (3.10- more than $15.0 \mathrm{GHz}$ ). But, the reviewed antenna size was larger than our proposed design. Alhawari [5] explained a planar antenna 
$(0.43 \lambda \times 0.43 \lambda)$ operating in UWB frequency. The measured impedance bandwidth was $8.70 \mathrm{GHz}$ (5.20-13.90 GHz), but the reported antenna did not cover the standard FCC approved ultrawideband frequency $(3.1-10.6 \mathrm{GHz})$ properly.

A planar antenna of pentagon-shaped was mentioned for UWB applications [6].In this antenna design, feed-line, pentagon stub and pentagon-shaped slot were combined foe achieving the impedance bandwidth of $124 \%$. But, because of having large ground plane, it is applied in small wireless devices limited. A planar antenna was proposed for UWB application where the overall antenna dimension was $30 \mathrm{~mm} \times 30 \mathrm{~mm}$ with covering 3.02 to $13.27 \mathrm{GHz}$ frequency range [7]. The antenna covered the complete UWB range with large dimension. A simple microstrip-fed monopole antenna was mentioned and studied for UWB applications with the antenna dimension of $33 \mathrm{~mm} \times 28 \mathrm{~mm}$ ranging from 3.0 to $12 \mathrm{GHz}$ [8]. The antenna covered the complete UWB range with large dimension. Ren [9] introduced a small elliptical ring antenna operating in the UWB frequency, which was fed with a coplanar waveguide. The reported antenna exhibited wideband characteristics with the raised length of the elliptical ring's major axis, covering an impedance bandwidth $5.70 \mathrm{GHz}(4.6-10.3 \mathrm{GHz})$. Although, it contains dimensions of compactness, standard FCC approved ultra-wideband frequency $(3.1-10.6 \mathrm{GHz})$ was not be covered properly.

In the research, a compact planar antenna is explained for UWB communications with planarpatterned structures printed on low cost dielectric material. The antenna exhibit nearly omnidirectional and sufficient impedance bandwidth with sharp current distribution. This antenna is a promising one for UWB applications.

\section{Antenna Design Architecture}

Fig. 1 displays the antenna structures with detailed configurations such as 3D view, front view, and back view. This reported design is fed with a microstrip line and printed on low cost dielectric material FR4 with $1.6 \mathrm{~mm}$ thickness and a permittivity of 4.6. The widths of the microstrip feed line are fixed at $2.72 \mathrm{~mm}$ and $3.55 \mathrm{~mm}$ on the upper portion and the lower portion, respectively. The designed antenna consists of planar-pattern structure, feeding, and a slotted ground plane. The patch is connected to the feed line. In this design, planar-pattern structure inspired radiating patch connected from the microstrip feed line is presented. This planar-pattern structure inspired patch acts as an impedance matching element to control the impedance bandwidth of the proposed antenna by creating additional surfaces of current paths in the antenna. A $50 \Omega$ SMA connector is connected to the end of the feeding strip and grounded to the edge of the ground plane. The proposed antenna is analyzed by the electromagnetic simulator HFSS, based on finite element method. 


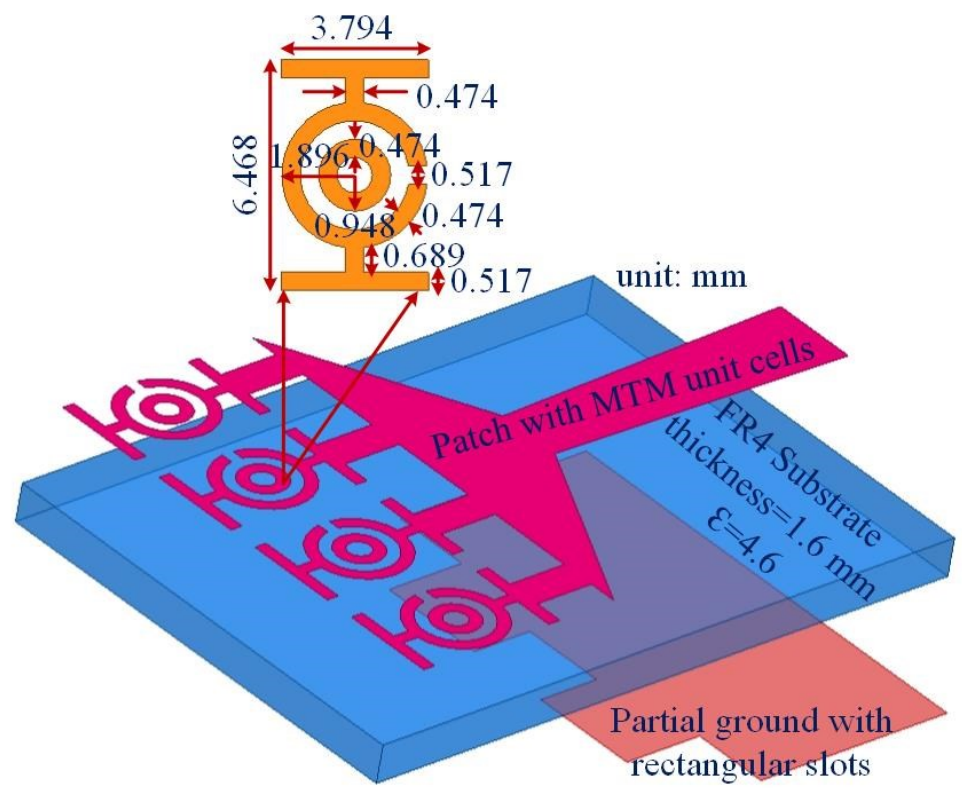

(a)

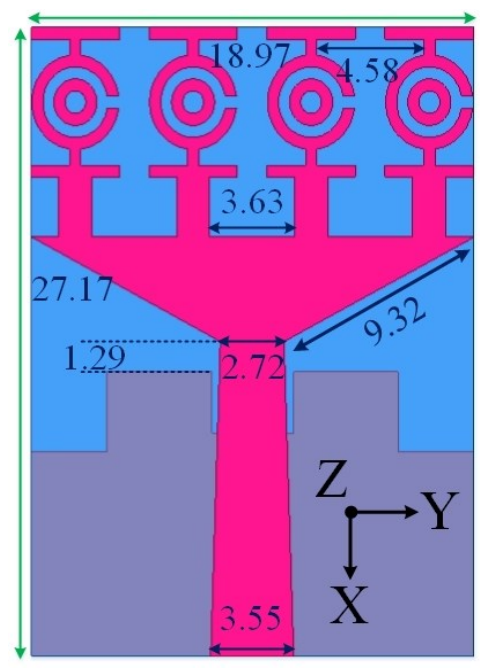

(b)

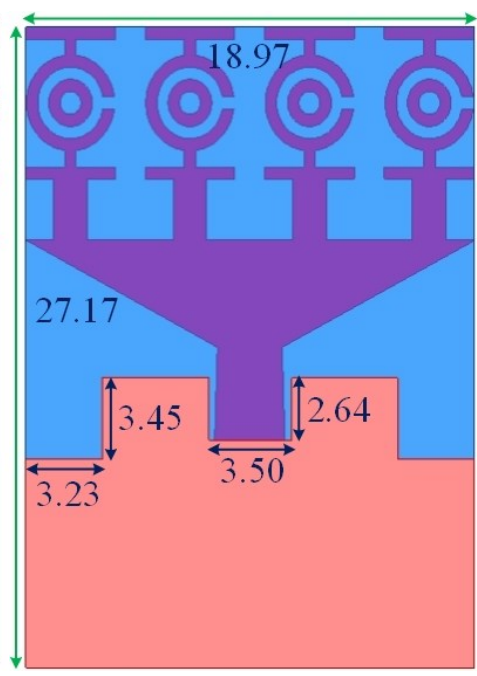

(c)

Fig. 1. The presented antenna (a) 3D view (b) Front view (c) Back view. 


\section{Results and Discussions}

The simulated and measured VSWR of the designed antenna is illustrated in Fig. 2. It is observed in the VSWR characteristics belonging to a bandwidth of $16.84 \mathrm{GHz}(3.07-19.71 \mathrm{GHz})$ from measurements and a bandwidth of $17.25 \mathrm{GHz}(3.15-20.40 \mathrm{GHz})$ from simulations, showing good agreement with simulated results. Fig. 3 exhibits the surface current at $3.5 \mathrm{GHz}$ and $8.3 \mathrm{GHz}$ frequency. The surface current is acquired taking into account the optimized design parameters. It can be observed from Fig. 3 that the concentration of the surface current distribution is very stable around the planar-pattern structure inspired patch, slot on ground and the feeding line. The 3D radiation pattern is illustrated in Fig.4. It can be observed that nearly omnidirectional and dipolelike radiation pattern can be realized on the both planes. The smith chart of the designed antenna is indicated in Fig. 5.

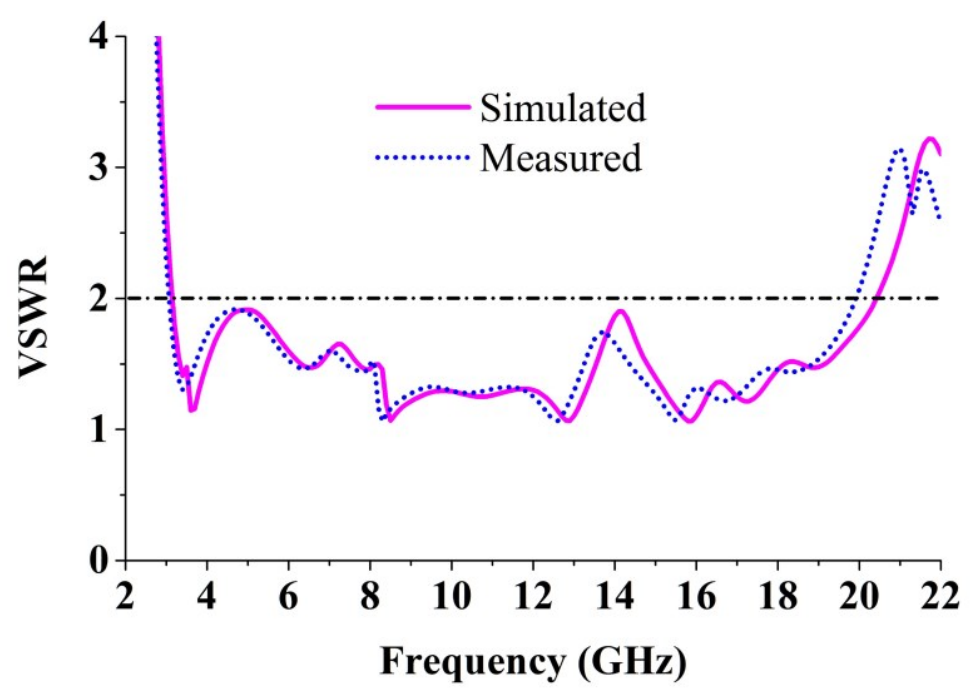

Fig. 2. VSWR of the designed antenna. 


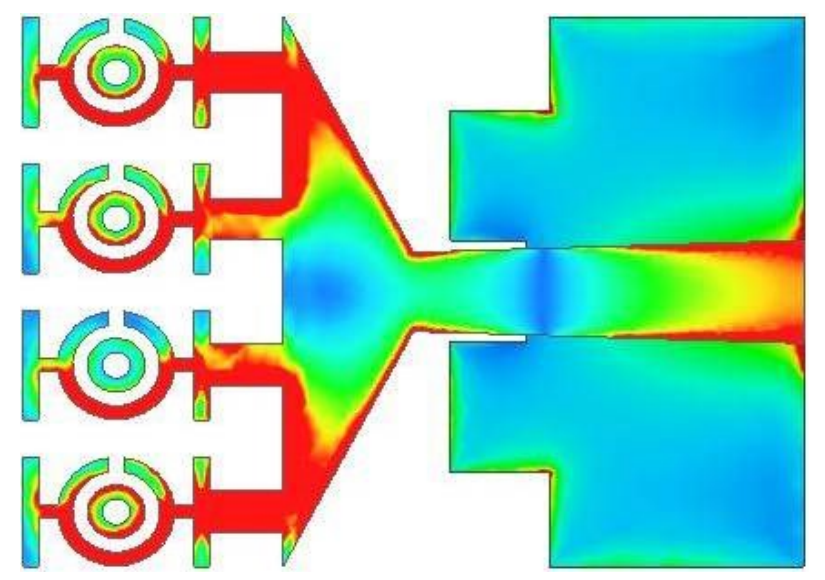

(a)

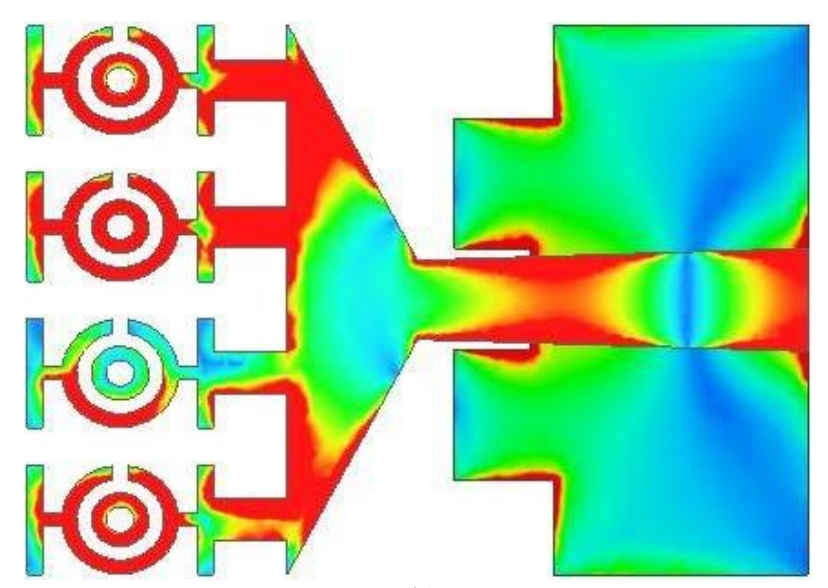

(b)

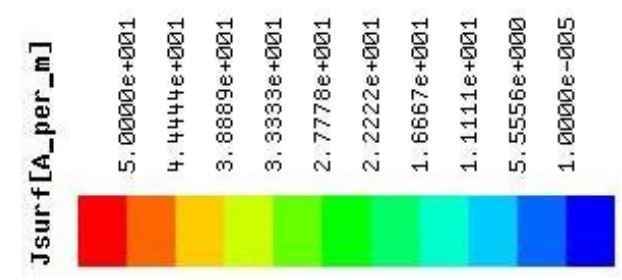

Fig. 3. Surface current at $\mathrm{GHz}$ at (a) $3.5 \mathrm{GHz}$, (b) $8.3 \mathrm{GHz}$. 

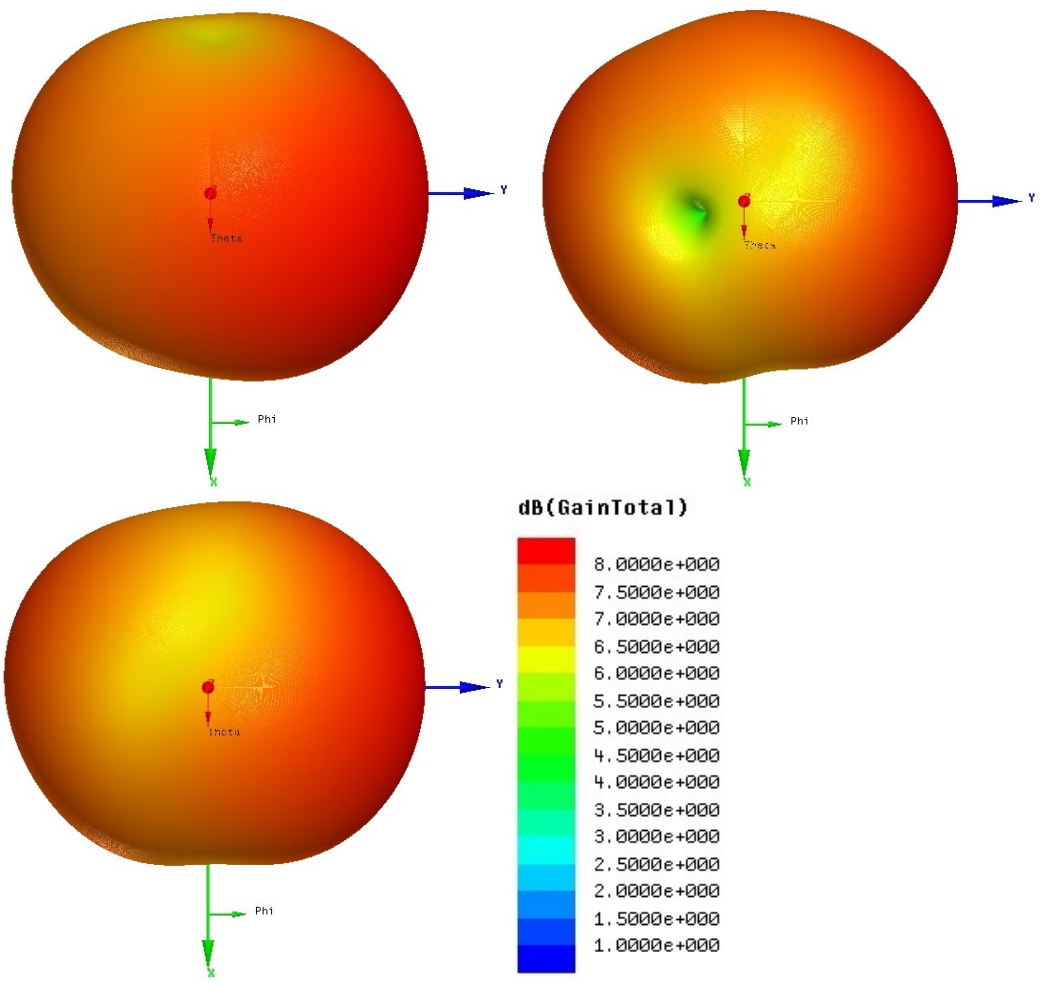

B (GainTota1)

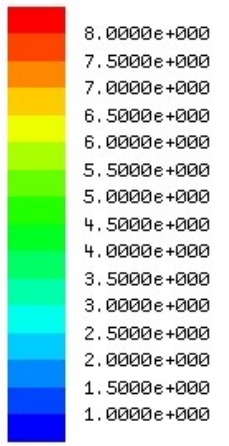

Fig. 4. The designed antenna with $3 \mathrm{D}$ radiation pattern at (a) $3.5 \mathrm{GHz}$ (b) $9 \mathrm{GHz}$.

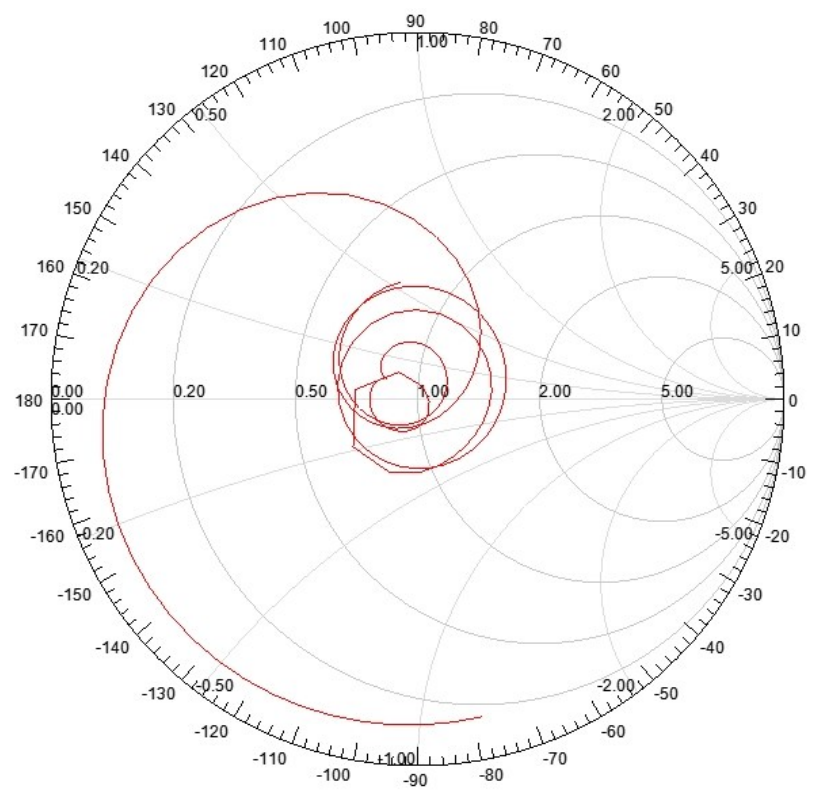

Fig. 5. The smith chart of the designed antenna. 


\section{Conclusion}

A monopole antenna with pattern-planar structure is introduced for UWB applications. The antenna has been matched properly with the impedance due to having planar-pattern structure, which leads the antenna to obtain an impedance bandwidth $16.84 \mathrm{GHz}$. The planar-pattern structures are placed in the right position on the radiating patch, which ensures compactness in the proposed antenna. Moreover, the designed antenna will be a promising one in UWB applications because of having sharp surface current, 3D radiation and better smith chart results.

\section{References}

[1] M. M. Islam, M. T. Islam, M. Samsuzzaman, and M. R. I. Faruque, "Compact metamaterial antenna for UWB applications," Electronics Letters, vol. 51, pp. 1222- 1224, 2015.

[2] M. Shakib, M. Moghavvemi, B. W. Mahadi, and W. N. Liza, "A Low Profile Patch Antenna for Ultrawideband Application," IEEE Antennas and Propagation Letters, vol. 14, pp. 1467-1470, 2015.

[3] M. A. W. Nordin, M. T. Islam, and N. Misran, "Design of a compact ultrawideband metamaterial antenna based on the modified split-ring resonator and capacitively loaded strips unit cell," Progress In Electromagnetics Research, vol. 136, pp. 157- 173, 2013.

M. T. Islam, M. M. Islam, M. Samsuzzaman, M. R. I. Faruque, and N. Misran, "A Negative Index Metamaterial-Inspired UWB Antenna with an Integration of Complementary SRR and CLS Unit Cells for Microwave Imaging Sensor Applications," Sensors, vol. 15, pp. 11601-11627, 2015.

A. R. H. Alhawari, A. Ismail, M. A. Mahdi, and R. S. A. R. Abdullah, "Miniaturized ultra-

[5] wideband antenna using microstrip negative index metamaterial," Electromagnetics, vol. 31, pp. 404-418, 2011.

S. K. Rajgopal and S. K. Sharma, "Investigations on ultrawideband pentagon shape microstrip slot antenna for wireless communications," Antennas and Propagation, IEEE Transactions on, vol. 57, pp. 1353-1359, 2009.

J. H. Lu and C. H. Yeh, "Planar Broadband Arc-Shaped Monopole Antenna for UWB System,"

[7] IEEE Transactions on Antennas and Propagation, vol. 60, pp. 3091-3095,

2012.

[8] J. X. Xiao, M. F. Wang, and G. J. Li, "A ring monopole antenna for UWB application," Microwave and Optical Technology Letters, vol. 52, pp. 179-182, 2010. Y.-J. Ren

[9] and K. Chang, "Ultra-wideband planar elliptical ring antenna," Electronics Letters, vol. 42, pp. 447-449, 2006. 